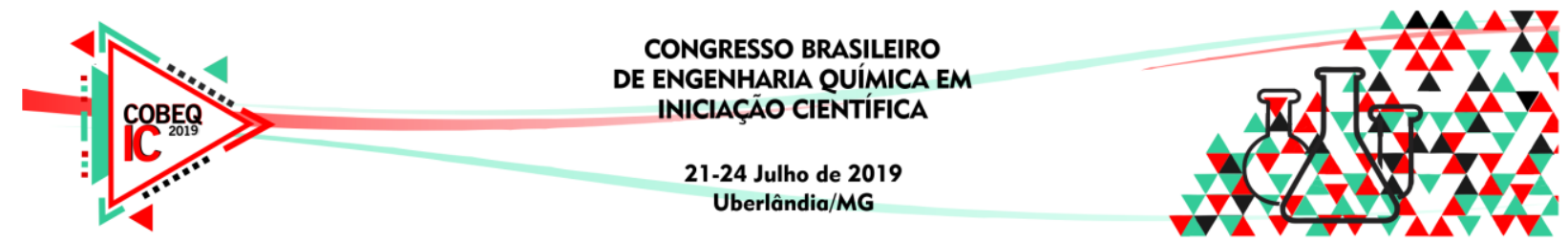

\title{
APLICAÇÃO DE EFLUENTE DE SORO DE QUEIJO NO CULTIVO DA MICROALGA CHLORELLA VULGARIS
}

\author{
L. RODRIGUES ${ }^{1}$, T. A. PIRES ${ }^{1}$ e F. R. X. BATISTA ${ }^{1}$ \\ ${ }^{1}$ Universidade Federal de Uberlândia, Faculdade de Engenharia Química \\ E-mail para contato: lauana.r@hotmail.com.br
}

\begin{abstract}
RESUMO - Nos últimos anos o estudo ficológico vem ganhando visibilidade devido a sua vasta aplicação. As microalgas, em especial, mostram-se promissoras, com significativa rentabilidade comercial em vista de uma ampla gama de bioquímicos por ela metabolizados. Elas podem ser empregadas na indústria alimentícia e na aquicultura, aumentando o valor nutricional de alimentos assim como de rações animais, na farmacêutica, devido a propriedades medicinais, na cosmética, e no desenvolvimento de técnicas biotecnológicas, incentivando pesquisas de cunho sustentável quanto ao aproveitamento de águas residuais no cultivo de microalgas. Por esta perspectiva, o cultivo de microalgas se torna alvo de otimização, a fím de se viabilizar métodos eficázes de multiplicação de biomassa algal. No presente estudo, utilizou-se efluente de soro de queijo na inoculação da microalga verde Chlorella vulgaris no objetivo de se avaliar a eficácia do crescimento algal em distintas concentrações de soro. Pela realização dos métodos, com o aumento da concentração do soro no meio de cultivo, obteve-se também um maior crescimento de biomassa. Averiguando, portanto, a promissoriedade de uso alternativo de tipos de águas residuais para a produção de microalgas.
\end{abstract}

\section{INTRODUÇÃO}

Dentre os temas recorrentes em pesquisas biotecnológicas nos últimos anos, atrelados a fatores ambientais, a aplicação das microalgas se destaca. O que se deve à capacidade de metabolizarem uma vasta gama de bioquímicos de seu meio de cultivo, por meio de absorção ou adsorção, devido à necessidade de manutenção nutricional ou mesmo por forças atrativas entre moléculas e superfície celular (Delrue et al., 2016). Por meio desses processos e da conversão fotossintética, as microalgas estão aptas a incorporar à biomassa diversos compostos orgânicos, dos quais citam-se proteínas, lipídios, carboidratos e pigmentos (Brennan; Owende, 2010).

Tal conjunto de substâncias em agregação torna tais microrganismos viáveis quanto à aplicação comercial, representando rentabilidade em muitas áreas. Seu emprego é verificado na aquicultura, na indústria e na pesquisa farmacêutica, devido a propriedades biomedicinais, e na cosmética, além de significativamente constituírem-se como incrementos na indústria alimentícia, agregando no valor nutricional de alimentos bem como de rações animais (Spolaore et al., 2006). 


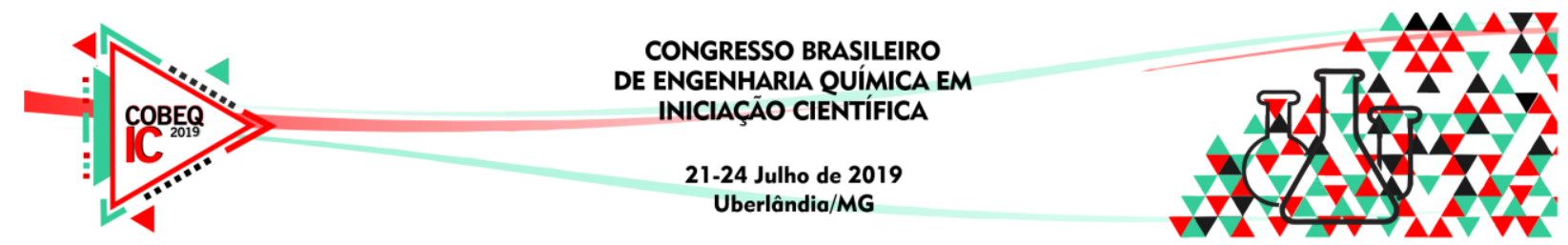

Dentre as formas de aplicação apresentadas acima, a última é a que mais tem visibilidade comercial, movimentando majoritariamente o capital investido no cultivo de microalgas, inserindo-se no meio alimentício no paradigma nutricional da sociedade, como produto saudável e de cunho nutracêutico (Milledge et al., 2012). O gênero Chlorella empregado no presente trabalho é um dos mais usufruído neste ramo, sendo produzido por mais de 70 empresas, somando um montante anual de cerca de 2 toneladas. Em grande parte, este cultivo é justificado pela comprovação biomédica dos benefícios de tais microalgas, sugerindo ação antitumoral, atenuação de úlceras gástricas, constipação, e ações preventivas contra aterosclerose e hipercolesterolemia (Milledge et al., 2012).

Outro uso de destaque é a assimilação de culturas de microalgas a efluentes líquidos, uma vez que as águas residuais portam quantidades significativas de matéria nutritiva, como nitrogênio, fósforo e carbono, que favorecem o crescimento algal devido às necessidades nutritivas/ metabólicas dos microrganismos (Batista et al. 2015). Constituindo, dessa forma, um outro prisma vislumbrado pela biotecnologia de microalgas, apontando para formas sustentáveis e alternativas de tratamento de afluente, atrelado à produção rentável de microalgas.

Atenta-se, dessa forma, para o incentivo ao uso de águas residuais de baixo custo, como é o caso de soro de queijo, proveniente de indústrias alimentícias, em métodos que permitam seu reuso, de forma a atribuir funcionalidade a matérias que inicialmente seriam destinadas a estações de tratamento. Assim, exemplifica-se com o uso de soro de queijo em meios de cultivo de microalgas, a fim de se otimizar o processo de crescimento de biomassa.

Tendo assim ilustrado a relevância do cultivo da microalga, bem como utilização funcional de efluentes líquidos, este trabalho buscou avaliar a eficiência de crescimento de biomassa algal ambientadas em diferentes concentrações de soro de queijo. A fim de se avaliar a promissoriedade do uso de águas residuais na produção de microalgas em especial da espécie Chlorella vulgaris.

\section{MATERIAIS E MÉTODOS}

Para tal estudo usou-se a microalga Chlorella vulgaris (BMAKD7), adquirida do Banco de Microrganismos de Aidar \& Kutner, que foi então inoculada em meio do tipo Bold Basal (BBM) modificado (Connon, 2007). Os ensaios foram realizados em Erlenmeyers de 250mL, contendo diferentes concentrações de soro de queijo (1, 10, 25, 50 e $100 \%$ v/v) diluído em meio BBM e uma concentração algal inicialmente de $0,1 \mathrm{~g}_{\mathrm{sv}} / \mathrm{L}$. Os frascos foram incubados por 6 dias, sob fotoperíodo de 12 horas e $22^{\circ} \mathrm{C}$. Ao longo do ensaio, medições de concentração mássica e sólidos totais foram realizadas. A determinação de sólidos totais foi realizada pelo método gravimétrico.

\section{RESULTADOS E DISCUSSÕES}

Após o desenvolvimento das metodologias de estudo, obtiveram-se os dados relativos ao crescimento da biomassa algal como segue na Tabela 1, pela qual percebe-se a existência de uma relação entre a composição do meio e a capacidade de crescimento da microalga 

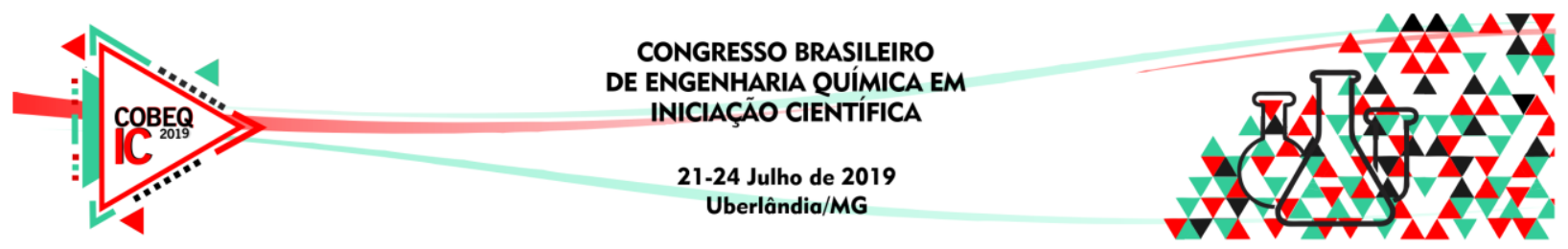

Chlorella vulgaris, que se evidencia no seu potencial de acúmulo mássico distinto para cada um dos acondicionamentos.

Tabela 1 - Concentração da biomassa da microalga Chlorela vulgaris ( $\mathrm{g}_{\mathrm{SV} / \mathrm{L}}$ ) em função do tempo e da composição do meio de cultivo com diferentes concentrações de soro de queijo.

\begin{tabular}{|c|c|c|c|c|c|c|}
\hline \multirow{2}{*}{ Dia } & \multicolumn{7}{|c|}{ Meio de cultivo } \\
\cline { 2 - 7 } & BBM & $1 \%$ & $10 \%$ & $25 \%$ & $50 \%$ & Soro \\
\hline 0 & 0,100 & 0,100 & 0,100 & 0,100 & 0,100 & 0,100 \\
\hline 3 & 0,131 & 0,158 & 0,526 & 0,811 & 0,662 & 0,250 \\
\hline 4 & 0,132 & 0,308 & 1,068 & 1,707 & 1,476 & 0,629 \\
\hline 5 & 0,135 & 0,401 & 1,087 & 1,747 & 1,507 & 0,655 \\
\hline 6 & 0,132 & 0,499 & 1,087 & 1,627 & 1,549 & 1,036 \\
\hline
\end{tabular}

Com base na comparação dos resultados obtidos entre os seis frascos, percebe-se a gradativa ascensão no acúmulo total de biomassa algal até que atingisse o ponto máximo que ocorreu no meio constituído em $25 \%$ de soro de queijo. Posteriormente a isto, um decrécimo a medida que se aumentava a organicidade dos meios, porém, ainda apresentando resultados bem expressivos de acúmulo de biomassa.

Tais resultados obtidos são compatíveis com dados já exitentes na literatura, quando a microalga em questão foi cultivada em meio inorgânico suplementado com solução em pó de soro de queijo não hidrolisada, atingindo cerca de 1,98 g gV/L após 4 dias (Abreu et al., 2012), porém sob condições de agitação, aeração, temperatura e outros fatores externos diferentes das aplicadas neste trabalho. O que leva a constatar, também, sobre a importância de averiguação das condições externas de cultivo, que interferem no crescimento da microalga.

Quanto a resultados de sólidos totais, tem-se a Tabela 2, que coerentemente mostra o maior acúmulo de sólidos nos frascos de $25 \%$ soro, validando os dados de biomassa algal obtidos na Tabela 1.

Tabela 2 - Sólidos solúveis totais em $\mathrm{g} / \mathrm{L}$ iniciais e finais do cultivo da microalga $C$. vulgaris em meio de cultivo padrão e em meios com diferentes concentrações de soro de queijo.

\begin{tabular}{|c|c|c|c|c|c|c|}
\hline Dia & BBM & $1 \%$ & $10 \%$ & $25 \%$ & $50 \%$ & Soro \\
\hline Dia 0 & 0,097 & 0,095 & 0,150 & 0,310 & 0,490 & 0,830 \\
\hline Dia 6 & 0,120 & 0,170 & 0,600 & 1,280 & 1,700 & 1,730 \\
\hline
\end{tabular}

Assim, é possível relacionar ambos os critérios investigados, levando a inferência de que a maior presença algal leva a uma maior concentrção de sólidos totais. Sendo que esse crescimento da biomassa se vincula a quantidade de matéria orgânica presente. Ou seja, pelos dados expostos, a proliferação da microalga gera uma maior quantidade de sólidos totais, assumindo, como verificado pelos resultados das tabelas 1 e 2, que estes dois parâmetros são diretamente proporcionais. 


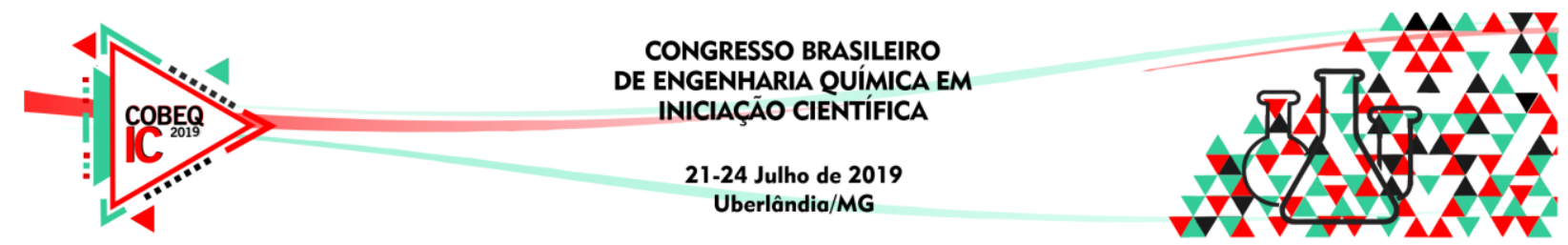

Sendo assim, comprova-se a eficiência de águas residuais no cultivo otimizado de microalgas, observada no âmbito da Chlorella vulgaris. A partir dos resultados, tem-se a concentração percentual de soro de queijo de $25 \%$ como melhor arranjo de ambientação para favorecer o crescimento do microrganismo. Além de se fazer viável economicamente, uma vez que o cultivo da $C$. vulgaris usando o principal subproduto da indústria de laticínios, soro de queijo, não requer a adição de carboidratos caros para o meio de cultura (Abreu et al., 2012).

Dessa forma, é evidenciado que os efluentes podem ser de grande serventia em utilizações alternativas e rentáveis. No caso do soro de queijo, tem-se um exemplo de água residual de baixo custo, e que ao invés de ser levado a processos dispendiosos de tratamento podem ser aplicados em biotecnologias a fim de se propiciar a otimização de cultivo de um produto de grande valor comercial, no caso representado pela $C$. vulgaris. Assim assimilando ganho mútuo na reutilização do resíduo, que terá taxas de organicidade reduzidas pelo metabolismo da microalga, o que auxilia como um método preliminar na futura adequação do meio líquido para descarte, atrelada ao ganho comercial e científico da produção algal.

\section{CONCLUSÕES}

Com base nos resultados obtidos é possível observar que a presença de soro de queijo no meio de cultivo influencia o crescimento da microalga Chlorella vulgaris, aumentando, consequentemente, a quantidade de sólidos totais. O que favorece o cultivo da microalga, com vistas à aplicação comercial da mesma, apropriando-se de compostos bioquímicos benéficos ao consumo e ao manejo de biotecnologias, que já possui expressividade em diversas áreas, e porta-se como potencial tecnológico de outras. Propiciando, assim, uma forma alternativa para utilização de águas residuais de baixo custo na produção de matéria prima rentável.

\section{AGRADECIMENTOS}

Os autores do presente trabalho agradecem à Universidade Federal de Uberlândia, à Faculdade de Engenharia Química, à Capes, CNPq e à FAPEMIG pelo apoio em infraestrutra e financeiro. Agradecem, também, à comissão organizadora do evento.

\section{REFERÊNCIAS}

ABREU, A. P.; FERnANDES, B.; VICENTE, A. A.; TEIXEIRA, J.; DRAGONE, G.. Mixotrophic cultivation of Chlorella vulgaris using industrial dairy wasteas organic carbon source. Bioresource Technology, v. 118, p. 61-66, 2012

BATISTA, A. P.; AMBROSANO, L.; GRAÇA, S.; SOUSA, C.; MARQUES, P. A. S. S.; RIBEIRO, B.; BROTEL, E. P.; CASTRO NETO, P.; GOUVEIA, L. Combining urban wastewater treatment with biohydrogen production - An integrated microalgae-based approach. Bioresour Technol, v. 184, p. 230-235, 2015.

BRENNAN, L.; OWENDE, P. Biofuels from microalgae - A review of technologies for production, processing, and extractions of biofuels and co-products. Renewable and Sustainable Energy Reviews. 2010. v.14, p.557-577. 


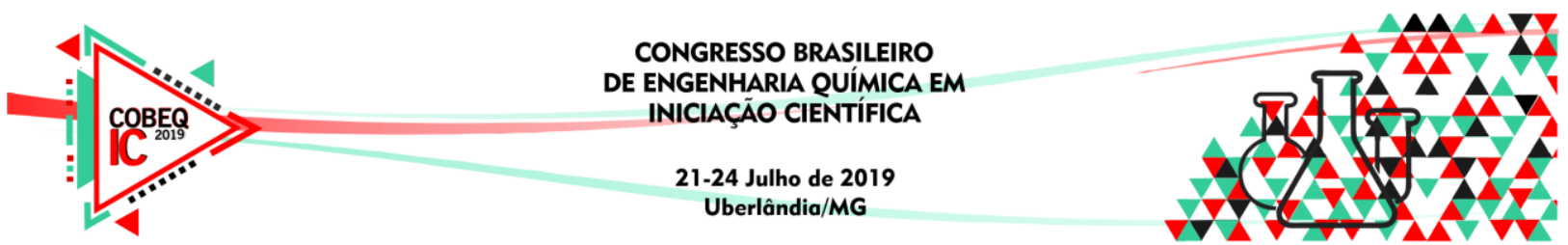

CONNON, R. Culturing of Chlorella vulgaris - Standard Operating Procedure, SOP on how to prepare Bold's Basal Medium (BBM), 2007. University of Reading.

DELRUE, F.; ÁlVAREZ-DÍAZ, P., D.; FON-SING, S.; FLEURY, G.; SASSI, J. The Environmental Biorefinery: Using Microalgae to Remediate Wastewater, aWin-Win Paradigm. Energies, v. 9, n. 132, 2016.

MILLEDGE, J. J. et al. Microalgae-commercial potential for fuel, food and feed. Food Science \& Technology, v. 26, n. 1, p. 28-30, 2012.

SPOLAORE, P.; JOANNIS-CASSAN, C.; DURAN, E.; ISAMBERT, A. Commercial applications of microalgae. Journal of Bioscience and Bioengineering Volume 101, Issue 2, February 2006, Pages 87-96. 